\title{
Controle de Acacia farnesiana e de Mimosa pteridofita em pastagem ${ }^{(1)}$
}

\begin{abstract}
Ricardo Carmona ${ }^{(2)}$, Bernardo Sayão Carvalho Araujo Neto ${ }^{(2)}$ e Roberto Carvalho Pereira(2)
Resumo - Conduziu-se um experimento com o objetivo de estudar a eficácia agronômica e econômica de herbicidas para o controle de duas sérias plantas daninhas de pastagens: Acacia farnesiana e Mimosa pteridofita. Os produtos utilizados, por meio de pincelamento no toco, foram o óleo diesel, óleo lubrificante usado de trator, solução aquosa de 2,4-D + picloram e solução oleosa de 2,4-D + picloram. À exceção do óleo lubrificante, os herbicidas foram testados em dois tamanhos de planta daninha e duas alturas de corte. Avaliaram-se a porcentagem de controle e o vigor de brotação das plantas não-controladas. Concluiu-se que o corte das plantas só é eficiente no controle das duas espécies, quando realizado no nível do solo e seguido da aplicação de herbicida específico, como o 2,4-D + picloram. O óleo diesel também controla totalmente ambas as espécies, e com menores custos que o 2,4-D + picloram, porém apenas quando aplicado nas plantas mais jovens. Há incompatibilidade entre o óleo diesel e o 2,4-D + picloram no controle das duas espécies. $\mathrm{O}$ óleo lubrificante usado não apresenta nenhum efeito herbicida em plantas adultas destas espécies.
\end{abstract}

Termos para indexação: herbicidas, óleo diesel, controle de plantas daninhas, eficácia.

\section{Control of Acacia farnesiana and of Mimosa pteridofita in pastures}

\begin{abstract}
An experiment was carried out to study the efficacy of herbicide treatments in controlling two serious pasture weeds: Acacia farnesiana and Mimosa pteridofita. The following herbicides were applied to the stump, after cutting: diesel oil, used engine lubricant oil, 2,4-D + picloram diluted in water or diesel oil and a control treatment without herbicide. All herbicide treatments were tested on two sizes of the plants and two heights of cutting, except the lubricant oil. The shrub control and sprouting vigor were evaluated in all treatments. The results showed that cutting of plants is effective only when it is carried out at the soil surface level and followed by a specific herbicide treatment, such as 2,4-D + picloram. Diesel oil controlled $100 \%$ of the younger plants of both species, at lower costs. There is an antagonistic effect between diesel oil and 2,4-D + picloram to control both species. The lubricant oil did not show any herbicide effects on these species.
\end{abstract}

Index terms: herbicides, diesel oil, weed control, efficiency.

\section{Introdução}

Entre as plantas daninhas consideradas mais problemáticas em áreas de pastagens instaladas estão as espécies perenes, que apresentam grande capacidade competitiva com as espécies forrageiras, e podem reduzir sobremaneira a produtividade das pastagens. Várias espécies daninhas assumem caráter preocupante conforme as condições edafoclimáticas. Na região dos cerrados, com maior intensi-

\footnotetext{
(1) Aceito para publicação em 2 de dezembro de 2000 .

(2) Universidade de Brasília, Faculdade de Agronomia e Veterinária, Caixa Postal 04508, CEP 70910-970 Brasília, DF. E-mail: rcarmona@unb.br, roberto@unb.br
}

dade nos estados de Goiás e Tocantins, ocorrem duas espécies bastante problemáticas - a esponja (Acacia farnesiana (Willd.)) e o angiquinho (Mimosa pteridofita Mart.) - que aparecem em densas populações, principalmente em pastagens degradadas ou em vias de degradação. A Acácia farnesiana predomina nas áreas mais úmidas de baixadas, e a M. pteridofita apresenta ocorrência mais acentuada nos locais mais secos e altos. Ambas pertencem à família botânica Leguminosae (Mimosaceae).

O controle mecânico, por meio de corte da parte aérea, é um método bastante utilizado pelos pecuaristas, apesar do baixo nível de controle observado na maioria das vezes (Deuber, 1997). Pode ser mecanizado ou manual, sendo, este último, realizado 
principalmente por pequenos produtores ou em regiões montanhosas (Dias, 1993). A maior ênfase no controle tem sido dada ao uso de herbicidas, por causa da sua eficácia, praticidade e vantajosa relação custo/benefício. O principal grupo de herbicidas utilizados em pastagens tem sido o dos mimetizadores das auxinas, por sua eficácia agronômica no controle de espécies de folha larga (Dias, 1993).

A mistura formulada mais utilizada no manejo de plantas daninhas perenes em pastagem tem sido o 2,4-D + picloram em solução aquosa. Ambos os componentes controlam ampla gama de espécies de folha larga, herbáceas, arbustivas e arbóreas, e são seletivos para gramíneas (Rodrigues \& Almeida, 1998). Essa mistura, comercialmente formulada, pode ser aplicada na copa das plantas ou no toco, após terem sido cortadas. A pulverização na copa pode ser feita em área total ou nas reboleiras mais infestadas. A pastagem deve ser previamente rebaixada, por meio de pastejo intensivo, na exposição das espécies infestantes. Quando a aplicação é realizada no toco, corta-se a árvore ou arbusto a $15-20 \mathrm{~cm}$ de altura, e, enquanto os vasos condutores (floema) estão ativos, pincela-se ou pulveriza-se a área cortada, com o herbicida na concentração de 4,0\% v/v (Rodrigues \& Almeida, 1998).

Os óleos vegetais ou minerais, acrescidos de emulsificantes e outros componentes, são largamente utilizados como adjuvantes em aplicações em pósemergência, aumentando a eficácia de um grande número de herbicidas (Nalewaja et al., 1986; Barrentine \& McWhorter, 1988; Gillespie \& Nalewaja, 1989; Bohannan \& Jordan, 1995; Nalewaja et al., 1995). Alguns tipos de óleo, como o diesel, apresentam efeito fitotóxico, por causarem a solubilização das paredes celulares, levando à desintegração celular e extravasamento do seu conteúdo para os espaços intercelulares, sendo classificados, por isso, como herbicidas orgânicos (Akobundu, 1987). Como exemplos de óleos minerais com efeito herbicida, pode-se citar o óleo diesel, querosene, solventes e misturas, os quais pertencem ao grupo químico dos hidrocarbonetos. Certos óleos, ácidos e sais são classificados como herbicidas de contato, por atuarem diretamente no local de contato, e exercem aí sua ação. O óleo diesel é usado como um herbicida nãoseletivo quando puro, ou como agente adjuvante no controle de algumas espécies, como, por exemplo, na mistura com herbicidas dinitrofenóis (Klingman \& Ashton, 1975). Os sintomas de ação dos óleos são o encharcamento das folhas, seguido de seu escurecimento e morte. Pode haver seletividade no tratamento com óleo, como é o caso da cenoura (Deuber, 1992).

Apesar da falta de recomendação oficial da pesquisa, alguns pecuaristas vêm utilizando, de forma empírica, o óleo diesel para o controle de plantas perenes em pastagem. Entretanto, a eficácia desse tratamento parece ser afetada por fatores como: espécie e idade da planta. $\mathrm{O}$ desenvolvimento de mais essa opção de manejo constitui importante avanço, graças a suas vantagens econômicas e à facilidade de aquisição em qualquer localidade.

O objetivo do presente trabalho foi estudar a eficácia agronômica e econômica de herbicidas no controle das plantas daninhas de pastagens: Acacia farnesiana e Mimosa pteridofita.

\section{Material e Métodos}

O experimento foi conduzido na Fazenda Vargem dos Patos, localizada na Bacia do Rio Paraim, Município de Formosa, GO, a aproximadamente $200 \mathrm{~km}$ de Brasília, DF. A propriedade apresentava extensas áreas de pastagens, com altas infestações naturais das espécies $A$. farnesiana $\mathrm{e}$ M. pteridofita, condição bastante comum na região. Os dados meteorológicos médios da região num período de 30 anos encontram-se na Tabela 1.

Os tratamentos químicos testados foram os seguintes: óleo diesel, óleo lubrificante usado de trator, 2,4-D + picloram diluído em água, 2,4-D + picloram diluído em óleo diesel, e testemunha sem aplicação. À exceção do óleo lubrificante, os outros quatro tratamentos com herbicidas foram testados em esquema experimental fatorial completo (4 herbicidas $\times 2$ espécies $\times 2$ tamanhos de planta $\times 2$ alturas de corte), em delineamento inteiramente casualizado. O tratamento com óleo lubrificante foi realizado, em ambas as espécies, apenas nas plantas maiores e no corte a $20 \mathrm{~cm}$ de altura.

Cada tratamento foi aplicado em 20 plantas de cada espécie, perfazendo um total de 680 plantas no experimento. Utilizaram-se plantas resultantes de infestações naturais de ambas as espécies, localizadas em áreas distintas, em dois tamanhos, selecionando-se as mais uniformes possíveis. Nenhum método de manejo havia sido aplicado 
a estas plantas durante todo o ciclo. As plantas consideradas menores, no caso de $A$. farnesiana, apresentavam altura de 1,8 a $2,5 \mathrm{~m}$ e diâmetro do tronco principal de $3 \mathrm{~cm}$, medido a $20 \mathrm{~cm}$ de altura em relação ao nível do solo. As maiores apresentavam ao redor de $4,0 \mathrm{~m}$ de altura, e o diâmetro do tronco, variando de 8,0 a $10,0 \mathrm{~cm}$. Quanto à M. pteridofita, as plantas menores apresentavam altura de $1,5 \mathrm{~m}$, com apenas um fuste de aproximadamente $1,5 \mathrm{a}$ $2,0 \mathrm{~cm}$ de diâmetro, a $20 \mathrm{~cm}$ do solo, e as maiores, $2,5 \mathrm{~m}$ de altura, com mais de um fuste, sendo o principal com diâmetro de 2,5 a $3,0 \mathrm{~cm}$. As alturas de corte foram de 0 e $20 \mathrm{~cm}$ em relação ao nível do solo.

Antes do corte, as plantas foram selecionadas e identificadas com uma estaca próximo à sua base, com cores distintas, de acordo com o herbicida a ser aplicado. As plantas de A. farnesiana foram cortadas com motoserra, em vista da rigidez do fuste, enquanto em M. pteridofita utilizou-se foice para o corte a $20 \mathrm{~cm}$ de altura, e enxadão para o corte ao nível de solo. Imediatamente após o corte, com a seiva ainda fresca, foi efetuado o pincelamento dos herbicidas no toco, utilizando-se uma esponja atada a um cabo de madeira, embebida com o produto (o tempo entre o corte e aplicação foi inferior a $1 \mathrm{mi}$ nuto). A quantidade utilizada foi suficiente apenas para umedecer bem a parte cortada, evitando-se o escorrimento do produto.

O óleo diesel e o óleo lubrificante foram aplicados sem diluição, e a formulação comercial contendo $240 \mathrm{~g} / \mathrm{L}$ de equivalente ácido de 2,4-D amina e $64 \mathrm{~g} / \mathrm{L}$ de equivalente ácido de picloram (Tordon 2,4-D 64/240) foi aplicada na concentração de $4 \% \mathrm{v} / \mathrm{v}$, tanto em água como em óleo diesel.

O corte e aplicação foram realizados em 27/3/1999 na A. farnesiana, e em 30/3/1999, na $M$. pteridofita. A equipe de trabalho foi composta por duas pessoas cortando as plantas (uma em cada altura), quatro pessoas aplicando os produtos (cada uma com um produto específico) e um supervisor para o controle do processo.

As avaliações foram feitas em 25/6/99 e 3/7/99 (aos 90 e 95 dias após a aplicação) na $A$. farnesiana e na M. pteridofita, respectivamente. Avaliaram-se a porcentagem de plantas controladas (ausência de brotação) e o vigor de brotação das plantas. De acordo com Frans \& Talbert (1977), considerou-se o nível de $100 \%$ como controle total das plantas daninhas; $90-99 \%$, controle eficiente; $80-89 \%$, controle aceitável; 50-79\%, controle não-aceitável, e 0-49\%, controle insuficiente. Para efeito da determinação de vigor de brotação, cada uma das 20 plantas que compuseram os tratamentos foi considerada como uma repetição. Este índice foi obtido pelo somatório do comprimento de todos os brotos para cada planta. Neste caso, aplicou-se a análise de variância aos dados, previamente transformados $(\mathrm{y}=\log \mathrm{x})$, seguida do teste de Tukey a $5 \%$ de probabilidade, quando havia mais de duas médias para comparação. Realizou-se também o teste F, para contrastar os resultados obtidos entre a aplicação de óleo lubrificante e a testemunha com plantas maiores, cortadas a $20 \mathrm{~cm}$, em ambas espécies.

Foi realizada a estimativa da eficácia agronômica e dos custos envolvidos em cada tratamento, com os valores convertidos em dólares americanos na época em que o experimento foi desenvolvido. Os cálculos foram feitos com vistas ao controle de 1.000 plantas, considerando-se o custo dos seguintes itens: mão-de-obra, herbicidas, combustível, e depreciação e manutenção da moto-serra. Considerou-se uma área densamente povoada com plantas adultas de cada espécie (mais de 2.000 plantas/ha), a mistura comercial de 2,4-D + picloram no valor de US\$22,00/L, o óleo diesel a US\$ 0,31/L e a mão-de-obra eventual a US\$11,11/dia (os valores em reais foram convertidos pela cotação de $\mathrm{R} \$ 1,80$ por dólar).

Tabela 1. Dados meteorológicos da Estação de Formosa, GO, durante o período de condução do experimento. Médias do período de 1961 a 1990. Localização: latitude $15^{\circ} 32^{\prime} \mathrm{S}$, longitude $47^{\circ} 20^{\prime} \mathrm{W}$, altitude 912 metros.

\begin{tabular}{lrrrrrr}
\hline Variável & Mar. & Abr. & Maio & Jun. & Jul. & Ano \\
\hline Temperatura máxima $\left({ }^{\circ} \mathrm{C}\right)$ & 28,0 & 27,7 & 27,2 & 26,2 & 26,2 & 27,7 \\
Temperatura mínima $\left({ }^{\circ} \mathrm{C}\right)$ & 17,6 & 15,8 & 13,9 & 13,3 & 14,5 & 16,8 \\
Temperatura média $\left({ }^{\circ} \mathrm{C}\right)$ & 22,4 & 22,0 & 20,8 & 18,4 & 18,9 & 21,5 \\
Precipitação (mm) & 183,8 & 107,6 & 28,8 & 3,7 & 5,8 & $1.485,3$ \\
Prec. máxima em 24 horas (mm) & 98,2 & 83,2 & 74,4 & 31,0 & 45,2 & 126,8 \\
Data da prec. máxima & $13 / 89$ & $2 / 65$ & $16 / 76$ & $7 / 81$ & $13 / 90$ & $18 / 1 / 79$ \\
Evaporação (mm) & 105,1 & 113,1 & 135,1 & 148,7 & 187,4 & 1721,1 \\
Umidade relativa (\%) & 78 & 75 & 70 & 65 & 58 & 69 \\
Insolação total (horas) & 187,0 & 216,0 & 243,1 & 245,9 & 260,6 & $2.407,7$ \\
\hline
\end{tabular}

Fonte: Inemet, Brasília, DF. 


\section{Resultados e Discussão}

O controle das espécies A. farnesiana e M. pteridofita variou bastante em decorrência do herbicida, altura de corte e tamanho das plantas (Tabelas 2 e 3 ). O corte das plantas sem aplicação posterior de herbicida não foi eficiente no controle de $A$. farnesiana, pois praticamente todas as plantas emitiram brotações, três meses após esse corte. Em M. pteridofita, o corte afetou de forma mais intensa a sobrevivência das plantas, especialmente quando executado rente ao solo e nas plantas menores. Entretanto, também não foi uma prática eficiente para esta espécie, pois o máximo de controle obtido foi de $50 \%$, o que é considerado inaceitável (Frans \& Talbert, 1977).

Estes resultados confirmam as observações de Dias (1993), de que o corte do sistema aéreo dos arbustos não apresenta controle satisfatório, de modo geral, pois ao ser cortado, o tronco volta a rebrotar em pouco tempo, e assim não é possível um controle a longo prazo.
A aplicação de herbicidas em seguida ao corte intensificou bastante o controle de ambas as espécies (Figura 1A). O óleo diesel controlou de forma total $(100 \%)$ as duas espécies, quando as plantas apresentavam-se no menor tamanho e foram cortadas rente ao solo (Tabela 2). Nessa situação, o tratamento com óleo diesel igualou-se ao tratamento com 2,4-D + picloram em solução aquosa, em termos de eficácia. O corte das plantas a $20 \mathrm{~cm}$ ocasionou uma grande redução na eficácia do óleo diesel para controlar as duas espécies. Da mesma forma, a eficácia do óleo diesel reduziu-se nas plantas maiores destas espécies. Aparentemente, o óleo lubrificante também não apresentou nenhum efeito no controle dessas espécies, quando aplicado nas plantas maiores, e no corte a $20 \mathrm{~cm}$, quando comparado com a testemunha.

A solução aquosa de 2,4-D + picloram controlou de forma total as duas espécies, independentemente do tamanho das plantas, quando o corte foi realizado rente ao solo. No corte a $20 \mathrm{~cm}$ do solo, em plan-

Tabela 2. Controle e vigor de brotação (somatório do comprimento de todos os brotos) das plantas de Acacia farnesiana e Mimosa pteridofita, em razão do herbicida utilizado, altura de corte e tamanho das plantas ${ }^{(1)}$.

\begin{tabular}{|c|c|c|c|c|c|c|}
\hline \multirow[t]{2}{*}{ Herbicida } & \multirow{2}{*}{$\begin{array}{l}\text { Altura } \\
\text { de corte } \\
(\mathrm{cm})\end{array}$} & \multirow{2}{*}{$\begin{array}{l}\text { Tamanho das } \\
\text { plantas }^{(2)}\end{array}$} & \multicolumn{2}{|c|}{ A. farnesiana } & \multicolumn{2}{|c|}{ M. pteridofita } \\
\hline & & & $\begin{array}{c}\text { Controle } \\
(\%)\end{array}$ & $\begin{array}{l}\text { Vigor } \\
(\mathrm{cm})\end{array}$ & $\begin{array}{c}\text { Controle } \\
(\%)\end{array}$ & $\begin{array}{l}\text { Vigor } \\
(\mathrm{cm})\end{array}$ \\
\hline \multirow[t]{4}{*}{ Ausente } & 0 & $\mathrm{P}$ & 5 & $170,4 b$ & 50 & $60,3 b$ \\
\hline & & $\mathrm{G}$ & 0 & $207,3 a$ & 26 & $231,7 \mathrm{a}$ \\
\hline & 20 & $\mathrm{P}$ & 0 & $155,6 \mathrm{~b}$ & 16 & $70,3 b$ \\
\hline & & $\mathrm{G}$ & 0 & $271,8 \mathrm{a}$ & 17 & $186,3 \mathrm{a}$ \\
\hline \multirow[t]{4}{*}{ Óleo diesel } & 0 & $\mathrm{P}$ & 100 & $0,0 \mathrm{~b}$ & 100 & $0,0 \mathrm{~b}$ \\
\hline & & $\mathrm{G}$ & 50 & $44,9 \mathrm{a}$ & 85 & $203,1 \mathrm{a}$ \\
\hline & 20 & $\mathrm{P}$ & 65 & $33,7 \mathrm{~b}$ & 80 & $56,0 \mathrm{~b}$ \\
\hline & & $\mathrm{G}$ & 20 & $137,4 \mathrm{a}$ & 75 & $116,3 \mathrm{a}$ \\
\hline \multirow{4}{*}{$\begin{array}{l}\text { 2,4-D + } \\
\text { picloram } \\
\text { em água }\end{array}$} & 0 & $\mathrm{P}$ & 100 & $0,0 \mathrm{a}$ & 100 & $0,0 \mathrm{a}$ \\
\hline & & $\mathrm{G}$ & 100 & $0,0 \mathrm{a}$ & 100 & $0,0 \mathrm{a}$ \\
\hline & 20 & $\mathrm{P}$ & 55 & $36,6 a$ & 100 & $0,0 \mathrm{~b}$ \\
\hline & & $\mathrm{G}$ & 50 & $18,7 \mathrm{a}$ & 95 & $2,0 \mathrm{a}$ \\
\hline \multirow{4}{*}{$\begin{array}{l}\text { 2,4-D + } \\
\text { picloram } \\
\text { em óleo diesel }\end{array}$} & 0 & $\mathrm{P}$ & 80 & $7,9 \mathrm{~b}$ & 95 & $15,0 \mathrm{~b}$ \\
\hline & & $\mathrm{G}$ & 70 & $16,5 \mathrm{a}$ & 95 & $82,4 \mathrm{a}$ \\
\hline & 20 & $\mathrm{P}$ & 55 & $26,1 \mathrm{~b}$ & 35 & $0,0 \mathrm{a}$ \\
\hline & & $\mathrm{G}$ & 10 & $170,4 \mathrm{a}$ & 10 & $0,0 \mathrm{a}$ \\
\hline Óleo lubrificante & 20 & $\mathrm{G}$ & 5 & 151,8 & 15 & 216,6 \\
\hline
\end{tabular}


tas de $M$. pteridofita, este herbicida apresentou controle total nas plantas menores, e eficiente nas maiores. Em A. farnesiana, o controle foi não-aceitável quando o corte foi realizado a $20 \mathrm{~cm}$, independentemente do tamanho das plantas. Esses resultados divergem da recomendação de $15-20 \mathrm{~cm}$ de altura, referente à aplicação desse herbicida no toco de árvores e arbustos (Rodrigues \& Almeida, 1998).

Observou-se efeito antagônico do óleo diesel com o 2,4-D + picloram no controle dessas espécies.

Tabela 3. Resumo das análises estatísticas dos resultados referentes ao vigor de brotação das plantas de Acacia farnesiana e Mimosa pteridofita em função do herbicida utilizado, altura de corte e tamanho das plantas (excluindo-se o tratamento com óleo lubrificante).

\begin{tabular}{lcrrrrrr}
\hline Causas de variação & GL & \multicolumn{2}{c}{ A. farnesiana } & & \multicolumn{2}{c}{ M. pteridofita } \\
& & \multicolumn{1}{c}{ F } & Pr>F & & F & Pr>F \\
\hline Herbicidas (H) & 3 & 50,35 & 0,0001 & & 100,17 & 0,0001 \\
Altura de corte (A) & 1 & 36,24 & 0,0001 & 4,11 & 0,1505 \\
Tamanho da pl. (T) & 1 & 85,78 & 0,0001 & 42,22 & 0,0001 \\
H x A & 3 & 20,03 & 0,0001 & 6,25 & 0,0056 \\
H x T & 3 & 8,11 & 0,0156 & & 3,15 & 0,0495 \\
A x T & 1 & 2,47 & 0,2432 & & 1,99 & 0,2956 \\
H x A x T & 3 & 7,75 & 0,0093 & 4,29 & 0,0126 \\
\hline CV (\%) & - & 25,2 & - & 29,3 & - \\
\hline
\end{tabular}

Esses resultados também divergem das recomendações de Rodrigues \& Almeida (1998), que preconizam a possibilidade de utilização de solução oleosa de 2,4-D + picloram para o pincelamento no toco, em espécies arbustivas. Por outro lado, os mesmos autores recomendam que não seja utilizado óleo diesel ou espalhante adesivo durante o pincelamento do picloram puro no toco.

O vigor de brotação das plantas também foi um parâmetro bastante adequado para avaliar a eficácia dos diversos tratamentos (Figura 1). Os resultados foram bem similares quando o parâmetro analisado foi a porcentagem de plantas controladas ou o vigor de brotação, o que mostra que mesmo as plantas que não foram controladas pelo tratamento com herbicida tiveram seu vigor reduzido (Tabela 2).

A interação significativa de segunda ordem (herbicidas $\mathrm{x}$ altura de corte $\mathrm{x}$ tamanho das plantas) pode ser explicada pela diferença que o tamanho das plantas apresentou no comportamento do óleo diesel e 2,4-D + picloram quando o corte foi efetuado rente ao solo (Tabela 3 ). Isto significa que o óleo diesel controlou de forma total as duas espécies apenas no corte rente ao solo e nas plantas menores.
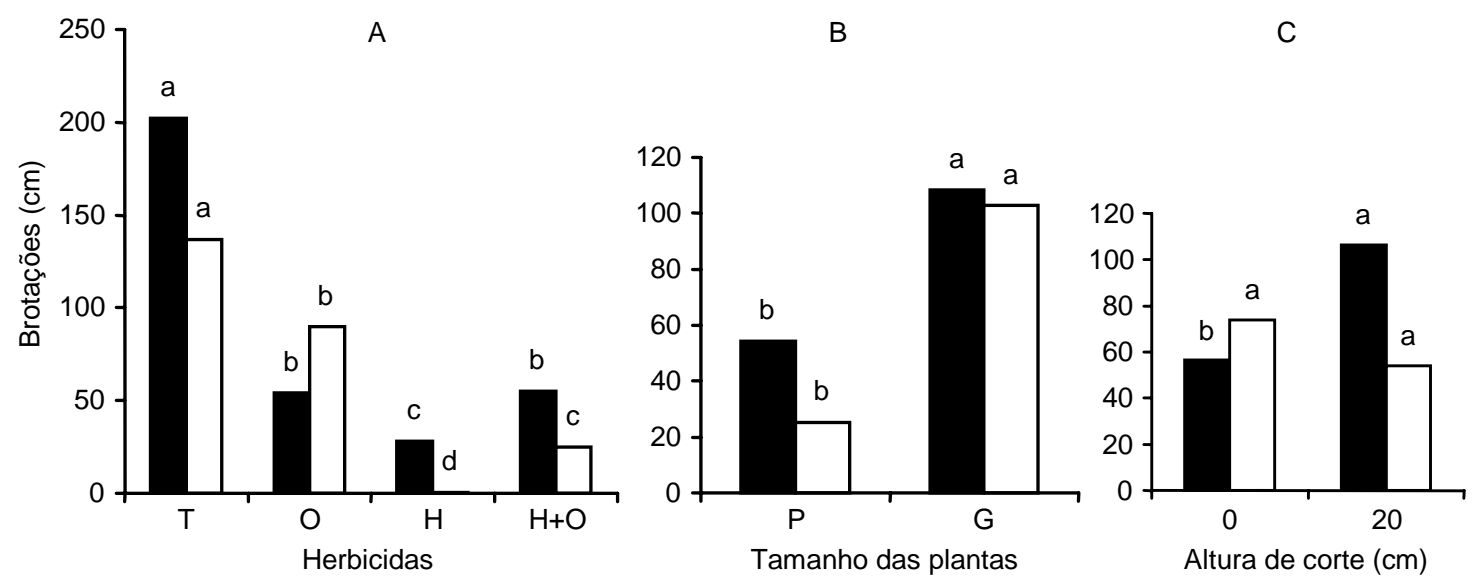

A. farnesiana $\square$ M. pteridofita

Figura 1. Vigor de brotação das plantas de Acacia farnesiana e Mimosa pteridofita em razão de: A) tipo de herbicida aplicado (T: testemunha; O: óleo diesel; H: 2,4-D + picloram; H + O: 2,4-D + picloram + óleo diesel); B) tamanho da planta; (C) altura de corte da planta. Médias com a mesma letra, em cada espécie, não diferem significativamente pelo teste de Tukey a $5 \%$ de probabilidade. 
Já o 2,4-D + picloram controlou $A$. farnesiana, quando o corte foi feito a $0 \mathrm{~cm}$, independentemente do tamanho das plantas; e em M. pteridofita, esse herbicida apresentou controle de eficiente a total, em ambas as alturas de corte e idades das plantas. De modo geral, o corte a $20 \mathrm{~cm}$ resultou em maior vigor de brotação na $A$. farnesiana, mas na M. pteridofita não houve diferença no vigor de brotação com relação à altura de corte (Figura 1C). As plantas maiores apresentaram vigor de brotação mais acentuado, em ambas as espécies (Figura 1B).

Todos os tratamentos envolvendo óleo diesel ou 2,4-D + picloram reduziram significativamente o vigor das brotações em relação à testemunha (Figura 1A). O óleo lubrificante não apresentou nenhum efeito no vigor de brotação de ambas as espécies, quando comparado com a testemunha $(\mathrm{F}=3,14$ e 0,$99 ; \operatorname{Pr}>\mathrm{F}=0,2133$ e 0,8812, na $A$. farnesiana e na M. pteridofita, respectivamente). Dessa forma, confirmou-se a falta de efeito herbicida do óleo lubrificante nas plantas adultas das duas espécies.

A estimativa de custos mostrou vantagem para o óleo diesel no controle das duas espécies, em relação ao 2,4-D + picloram (Tabela 4). Nas plantas menores das duas espécies, cortadas rente ao solo, o óleo diesel e a solução aquosa de 2,4-D + picloram apresentaram a mesma eficácia agronômica, porém a um custo próximo a $30 \%$ inferior para o óleo diesel. Essa redução de custos é bastante significativa, apesar de os resultados evidenciarem que o óleo diesel não pode substituir o 2,4-D + picloram em todas as situações. O 2,4-D + picloram, apesar de mais caro, é mais recomendável que o óleo diesel, para o controle das plantas consideradas grandes nas duas espécies, em vista de sua maior eficácia.

O óleo diesel é descrito na literatura como um herbicida de contato destruidor de membranas e parede celular (Akobundu, 1987; Deuber, 1992). Entretanto, esse mecanismo de ação não explica seu efeito quando pincelado no toco dessas espécies. A falta de brotação e o secamento do toco e das raízes mostram que este tratamento levou as plantas à morte. Isto sugere uma translocação do óleo diesel às raízes das plantas, ou seja, que o produto apresenta uma ação sistêmica, quando aplicado no toco com a seiva ainda fresca.

Outro aspecto muito importante a ser considerado neste contexto é a toxicidade e persistência dos herbicidas em relação ao aplicador e ao ambiente. O 2,4-D + picloram apresenta alta persistência no solo, especialmente por causa do picloram (dois a três anos). Além disso, apresenta alta toxicidade (classe I - faixa vermelha) (Rodrigues \& Almeida, 1998), o que é um problema, especialmente nos dias de hoje, pois a preocupação com a sustentabilidade das atividades agropecuárias é muito grande. Apesar do óleo diesel não ter sido devidamente estudado nesse aspecto, o mesmo vem sendo usado pelo homem, há muito tempo, como combustível, sem maiores problemas relatados.

A viabilização do uso do óleo diesel como herbicida reside na facilidade de sua obtenção em praticamente todas as regiões do mundo, em qualquer época do ano. Dessa forma, diminuem os riscos de perda da época mais favorável para o uso do herbicida em função de sua falta no comércio.

Tabela 4. Estimativa de custos envolvidos (R\$) no corte e aplicação dos herbicidas para o controle de 1.000 plantas de Acacia farnesiana e Mimosa pteridofita em dois estágios de crescimento $^{(1)}$.

\begin{tabular}{lccccc}
\hline Tratamento & \multicolumn{2}{c}{ A. farnesiana } & & \multicolumn{2}{c}{ M. pteridofita } \\
\cline { 2 - 3 } \cline { 5 - 6 } & $\mathrm{P}$ & $\mathrm{G}$ & & $\mathrm{P}$ & $\mathrm{G}$ \\
\hline Óleo diesel & 31,86 & 41,55 & & 36,16 & 47,13 \\
2,4-D + picloram em água & 46,30 & 64,82 & & 49,34 & 59,50 \\
2,4-D + picloram em óleo diesel & 63,99 & 87,47 & & 69,27 & 89,34 \\
Óleo lubrificante & 25,40 & 30,47 & & 28,31 & 38,34 \\
\hline
\end{tabular}

(1)P: A. farnesiana: altura de 1,8 a 2,5 m e diâmetro do tronco principal de $3 \mathrm{~cm}$ (a $20 \mathrm{~cm}$ do solo); $M$. pteridofita: altura de $1,5 \mathrm{~m}$, com um fuste de 1,5 a $2,0 \mathrm{~cm}$ de diâmetro (a $20 \mathrm{~cm}$ ); G: A. farnesiana: altura de 4,0 m e diâmetro do tronco de 8,0 a $10,0 \mathrm{~cm} ; M$. pteridofita: altura de $2,5 \mathrm{~m}$ com diâmetro do fuste principal de 2,5 a $3,0 \mathrm{~cm}$ 


\section{Conclusão}

Acacia farnesiana e Mimosa pteridofita são controladas eficientemente quando cortadas ao nível do solo e o toco é pincelado com solução aquosa de 2,4-D + picloram, na concentração de 4\%, em plantas com qualquer tamanho, ou com óleo diesel puro, desde que a altura máxima das plantas seja de 2,5 m para $A$. farnesiana e 1,5 m para $M$. pteridofita.

\section{Agradecimentos}

Ao Sr. Bernardo Sayão Carvalho Araújo Filho, pela cessão de área de sua propriedade, e da mão-deobra necessária para a realização do experimento.

\section{Referências}

AKOBUNDU, I. E. Weed science in the tropics: principles and practices. Norwich: J. Wiley, 1987. $522 \mathrm{p}$.

BARRENTINE, W. L.; McWHORTER, C. G. Johnsongrass (Sorghum halepense) control with herbicides in oil diluents. Weed Science, Champaign, v. 36, p. 102110,1988

BOHANNAN, D. R.; JORDAN, T. N. Effects of ultralow volume application on herbicide efficacy using oil diluents as carriers. Weed Technology, Champaign, v. 9 , p. $682-688,1995$.
DEUBER, R. Ciência das plantas infestantes: fundamentos. Jaboticabal: Funep, 1992. v. 1

DEUBER, R. Ciência das plantas infestantes: manejo. Campinas: Degaspari, 1997. v. 2.

DIAS, F. N. B. Invasoras em pastagens. São Carlos: Embrapa-CPPSE, 1993. 13 p. (Circular Técnica, 4).

FRANS, R. E.; TALBERT, R. Measuring plant responses. In: TRUELOVE, B. (Ed.). Research methods in weed science. 2. ed. New York: Southern Weed Science Society, 1977. $225 \mathrm{p}$.

GILLESPIE, G. R.; NALEWAJA, J. D. Influence of 2,4-D and MCPA formulations and oil on diclofop phytotoxicity. Weed Science, Champaign, v. 37, p. 380-384, 1989.

KLINGMAN, G. C.; ASHTON, F. M. Weed science: principles and practices. New York: J. Wiley, 1975. 431 p.

NALEWAJA, J. D.; PRACZYK, T.; MATYSIAK, R. Surfactants and oil adjuvants with nicosulfuron. Weed Technology, Champaign, v. 9, p. 689-695, 1995.

NALEWAJA, J. D.; SKZYPEZAK, G. A.; GILLESPIE, G. R. Absorption and translocation of herbicides with lipid compounds. Weed Science, Champaign, v. 34, p. 564$568,1986$.

RODRIGUES, B. N.; ALMEIDA, F. S. Guia de herbicidas. 4. ed. Londrina: Ed. dos Autores, 1998. 648 p. 